\title{
Centripetalis recessive dystrophic epidermolysis bullosa
}

INSERM

\section{Source}

INSERM. (1999). Orphanet: an online rare disease and orphan drug data base.

Centripetalis recessive dystrophic epidermolysis bullosa. ORPHA:89841

Centripetalis recessive dystrophic epidermolysis bullosa (RDEB-Ce) is an extremely rare subtype of dystrophic epidermolysis bullosa (DEB, see this term), characterized by blistering which begins acrally and then progressively spreads toward the trunk. 